\title{
The Relationship between Myopia and Ocular Alignment among Rural Adolescents
}

\author{
Li-Ju Lai1,2,3, Wei-Hsiu Hsu',3, Chien-Neng Kuo1,3, Rei-Mei Hong', Mei-Yen Chen ${ }^{{ }^{*}}$ \\ ${ }^{1}$ Department of Ophthalmology, Chang Gang Memorial Hospital, Taoyuan, Taiwan \\ ${ }^{2}$ Sports Medicine Center, Department of Orthopedic Surgery, Chang Gung Memorial Hospital, Taoyuan, Taiwan \\ ${ }^{3}$ School of Medicine, Chang Gang University, Taoyuan, Taiwan \\ ${ }^{4}$ Nursing Department, Chang Gung University of Science and Technology, Puzi City, Taiwan \\ ${ }^{5}$ College of Nursing, Chang Gung University of Science and Technology, Puzi City, Taiwan \\ Email: Iynnlai@cgmh.org.tw, 7572@cgmh.org.tw, k771376@cloud.cgmh.org.tw, mhong@mail.cgust.edu.tw, \\ "meiyen@gw.cgust.edu.tw
}

Received 18 September 2014; revised 19 October 2014; accepted 6 November 2014

Copyright (C) 2014 by authors and Scientific Research Publishing Inc.

This work is licensed under the Creative Commons Attribution International License (CC BY).

http://creativecommons.org/licenses/by/4.0/

(c) () Open Access

\section{Abstract}

Purpose: The prevalence of myopia in school-age children and rural area in Taiwan has increased dramatically. The aim of this study was to explore the associated factors of myopia in rural adolescents. Methods: A cross sectional design with a rural junior high student was invited to participate in this study. The relationship between refraction error (RE), spectacle fitting condition, and ocular alignment was determined by stereoacuity. The RE was determined using autorefractor. The ocular alignment was evaluated by cover-uncover test. Stereoacuity was measured by Titmus test. The examination about spectacle fitting included the lens power, lens transparency, pupil distance, frame size, and distortion of the frame. Multiple linear regression was used to determine the effect of the spectacle suitability and ocular alignment on the RE and stereoacuity. Results: The prevalence of myopia was $78 \%$ in a total of 338 adolescents, and the incidence of high myopia ( $\leq-6$ Diopter, D) accounted for $10.2 \%$. Participant worn poor-fitting spectacles were found with more myopia $(-3.95 \mathrm{D}$ vs $-3.42 \mathrm{D}, \mathrm{p}=\mathbf{0 . 0 2})$. The exophoria or exotropia significantly increased $\mathrm{RE}$ $(p<0.01)$. The eye position was significantly associated with decreased steroacuity function $(p=$ 0.03). Head position demonstrated to have a significant relationship with stereoacuity $(p=0.03)$. Conclusions: Good-fitting spectacles provided a good visual function and were associated with less RE condition. Exotrope showed a significant correlation with myopia and stereoacuity. The health care providers should be aware of the ocular alignment in myopic suffers.

\section{Keywords}

Myopia, Ocular Alignment, Adolescents, Rural Areas

\footnotetext{
${ }^{*}$ Corresponding author.
} 


\section{Introduction}

The prevalence of myopia in Asian school-age children has increased dramatically over the past few decades, and myopia is now one of the most common ocular disorders in Asia [1]-[4]. National myopia surveys conducted in Taiwan found that the prevalence of myopia had progressively increased over time [5]. From 1983 to 2000, the prevalence of myopia for 7-year-old children increased from 5.8\% to $20.4 \%$ and that for 12 -year-old children has increased from $36.7 \%$ to $60.7 \%$. The prevalence of myopia for students between the age of 16 and 18 increased from $76.8 \%$ to $84.0 \%$. Even though literature has suggested that myopia is a genetic disease [6] [7], some environmental factors might result in myopia progression, such as inappropriate fitting of spectacles and life style [8] [9]. However, not much literature points to the relationship between spectacle fitting condition and the myopia.

Population-based data in children suggested that Asian populations, especially those of Chinese ethnicity, might be more susceptible to myopia as compared to western populations [2]. In the areas of Hong Kong, Taiwan, and Singapore, the prevalence of myopia ranges from $45 \%$ to $81 \%$ in Chinese children [10]-[13], while 20\% in United States [14] and 36.8\% in Greece [15]. On the other hand, the presentations of ocular alignment were also different. Esotropia was twice as common as exotropia in the western countries [16]-[18], while exotrope was found much more than esotrope in Hong Kong and Singapore [19]-[21]. It has been suggested that patients with exophoria often convert more pseudomyopia [22]. Despite the Chinese population having both higher prevalence in myopia and exotropes, it remained unclear whether the ocular alignment was associated with the refractive error. Therefore, the purpose of the current study was to investigate the effect of spectacle suitability, ocular alignment, head position on the refractive error condition and the stereoacuity among adolescents in rural southern Taiwan.

\section{Materials and Methods}

\subsection{Study Design and Population}

This study is part of a health promotion for community health development around areas in south-western coastal Yunlin County, Taiwan. Using a descriptive cross-sectional design, this school-based survey was implemented at school health center from October to December, 2012. All of the 7th grade students were encouraged and invited to participate in this study. A total of 361 students were invited.

\subsection{Procedure and Ethical Considerations}

This study was conducted with a corporate private hospital through the community health screening program, and approved by the institutional review board ethical committee (Chang-Gung Memorial Hospital Ethics Committee No 100-3726 B). Informed consents were obtained from student and one of their parents or grandparents after explanation the purpose and procedures of the study. Two ophthalmologists and six research assistants implemented this program for 10 weeks. All research assistants were trained for 4 hours by the investigators. Research assistants were senior nursing students in a post-RN bachelor of nursing degree program.

\subsection{Ocular Examination}

The ocular examination included visual acuity (VA), visual acuity after glasses (VApG), and the refractive error was measured by the auto-refractor (RK8800, Topcon Co., Japan). Myopia was defined as $-1.0 \mathrm{D}$ or more. Myopia in both the horizontal and vertical meridians was measured following the guidelines of the Eye Diseases Prevalence Research Group [23]. The ocular alignment was examined by cover-uncover test at distance of 100 cm for latent deviation. The two eye ball position was evaluated. The students sat in their neutral position before grid chart and photography was done. The eyeball position was determined as the same high, left eye ball higher than right eye, or right eye ball higher than the left eye. Slit-lamp biomicroscopy and direct ophthalmoloscopy were performed to evaluate the ocular condition.

\subsection{Spectacles Evaluation}

The spectacles had been checked for the lens power, the pupil distance (PD), and the frame structure. The spectacle condition of the children was photographed for the evaluation (D70, Nikon Co., Japan). Good fitting of 
spectacles was defined as following: 1) proper glasses prescription correlated with their refraction condition ( $\leq 1.0 \mathrm{D})$ and good quality of lens transparency; 2) suitable glasses frame size for the head and face; 3 ) acceptable pupil distance ( $\leq 2 \mathrm{~mm}$ ); and 4 ) eyeglass frame neither tilting nor distorted (Figure 1).

\subsection{Stereoacuity Evaluation}

Titmus stereotest (Stereo Optical Co., Chicago, IL, USA) was used in this study. Participants were instructed to wear polaroid glasses at a distance of $40 \mathrm{~cm}$. The disparity of circle of Titmus was 800, 400, 200, 140, 100, 80, 60 , 50, and 40 seconds of arc (seconds) [24]. Stereoacuity values, ranging from 40 to 800 arcsec, were transformed to log arcsec for the purpose of analysis because the stereoacuity thresholds were not on a linear scale [25].

\subsection{Statistical Analysis}

To evaluate the risk factors for myopia, multivariate statistical analyses were performed. Odds ratios (OR) for myopia and their 95\% confidence intervals (CI) were calculated as an approximation of the relative risk estimates. The factors included in the multivariate model were: age, sex, stereo visual acuity, eye position, head position. Comparisons in visual acuity between good and poor glasses fitting were performed using student t-test. Comparisons in visual acuity between different ocular alignments were performed using ANOVA. The significance was set at 0.05. All calculations were performed with use of SPSS for Windows software (version 17; SPSS, Chicago, Illinois, USA).

\section{Results}

Excluding incomplete data, a total of 338 junior high students enrolled in this study, including 166 boys (49\%) and 172 girls (51\%). They were all seventh grade students with an average age of 13 (range 11 - 14 years old)

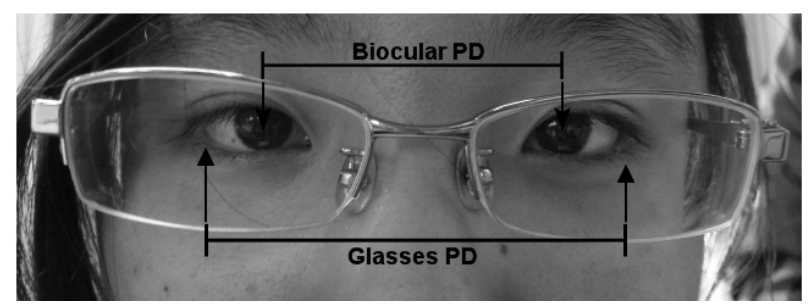

(a)

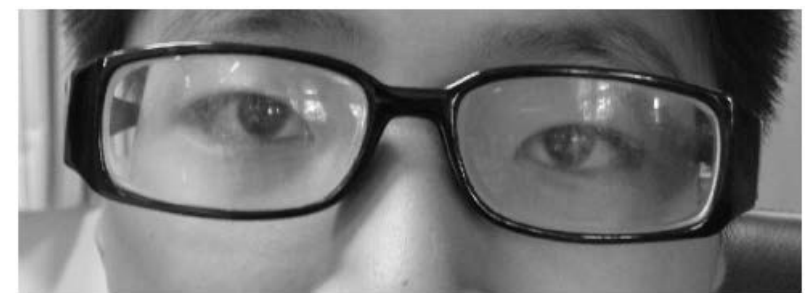

(b)

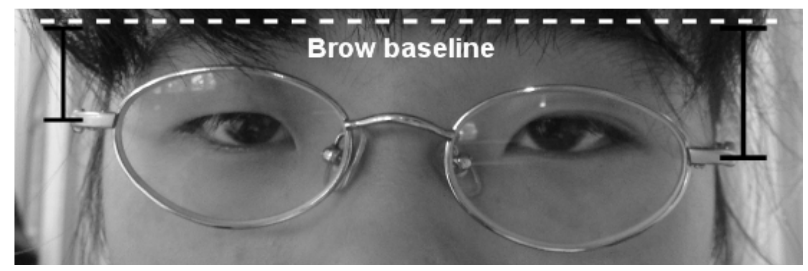

(c)

Figure 1. The poor suitability of spectacles. (a) The glasses PD was greater than the binocular PD; (b) Poor quality of lens transparency; (c) The glass frame was tilting. 
(Table 1). The students did not have any ocular diseases except for the refraction error and the ocular malalignment. The mean refraction condition was $-2.17 \mathrm{D}$ ( $\mathrm{SD} \pm 1.86$ ). Sixty-nine students (20\%) had emmetropia, and the mean refraction was $-0.31 \mathrm{D}$ ( $\mathrm{SD} \pm 0.32$ ). Only eight students $(2 \%)$ had hyperopia with the mean refraction + 1.33D ( $\mathrm{SD} \pm 1.08$ ). Two-hundred and sixty-one students (78\%) had myopia with the mean refraction $-2.77 \mathrm{D}$ (SD \pm 1.07$)$. Only 15 students (4.54\%) kept using the cycloplegic agents before sleep. No students wore orthokeratology lenses or contact lenses. Among the myopia group under the autorefraction examination (Figure 2(a)), 312 eyes (60.0\%) belonged in the low myopia group ( 0 - -3D), 189 eyes (36.2\%) included in the moderate myopia group ( $-3 \mathrm{D}--6 \mathrm{D})$, and 21 eyes $(4.0 \%)$ were in the high myopia group ( $\leq-6 \mathrm{D})$.

One hundred and seven students (32\%) who were diagnosed with myopia did not wear spectacles and had the mean refraction of $-1.58 \mathrm{D}$ ( $\mathrm{SD} \pm 0.78$ ) (Table 2). One hundred and fifty-four students (46\%) had spectacle prescriptions and the mean refraction was $-3.60 \mathrm{D}$ ( $\mathrm{SD} \pm 1.62)$. However, $42.8 \%(66 / 154)$ of these students had poor fitting spectacles with mean refraction of $-3.95 \mathrm{D}(\mathrm{SD} \pm 1.86)$. The students in the good fitting spectacles group had the mean refraction error of $-3.42 \mathrm{D}(\mathrm{SD} \pm 1.39$ ). By the lineal regression analysis, the relationship within the myopia refraction and spectacle prescription revealed a moderate association $\left(\mathrm{R}^{2}=0.671, \mathrm{p}<0.01\right)$ (Figure 2(b)). The spectacle prescription generally presented undercorrection by $75 \%$ in this study. Under the condition, if the refraction showed $-2.0 \mathrm{D}$, then the spectacle prescription was $-1.21 \mathrm{D}$. But, if the refraction was $-6.0 \mathrm{D}$, the spectacle fitting became $-4.28 \mathrm{D}$.

According to the multiple linear regression analysis (Table 3), the spectacle suitability and ocular alignment demonstrated significant effect on refractive error condition $(\mathrm{p}<0.05)$, while the gender and the head position did not ( $p=0.06 \& p=0.37)$. Specifically, the effects of ocular alignment were examined first. The incidence of exophoria accounted for $48.79 \%$, which was higher than the incidence of orthotropia (40.61\%) (Figure 3(a)). The exotropia rate was $7.58 \%$, and both of the esophoria or esotropia were $1.22 \%$. Two students were diagnosed with heterotropia $(0.61 \%)$. The mean refraction in the group of orthotropia, exophoria, and exotropia was $-1.34 \mathrm{D}$

Table 1. Demographic characteristics $(\mathrm{N}=338)$.

\begin{tabular}{lcc}
\hline Variables & Mean (SD) & $\%$ \\
\hline Age (years) & $12.75(1.30)$ & \\
Mean spherical equivalent (MSE) & $-2.17(1.86)$ & \\
Stereoacuity (second) & $120.47(183.63)$ & \\
Gender & & \\
$\quad$ Male $(\mathrm{n}=166)$ & $49 \%$ \\
Female $(\mathrm{n}=172)$ & $51 \%$ \\
Refraction error & \\
$\quad$ Myopia ( $\mathrm{n}=261)$ & $78 \%$ \\
Hyperopia (n $=8)$ & $2 \%$ \\
$\quad$ Emmetropia (n=69) & $20 \%$ \\
Head position (normal) $(\mathrm{n}=293)$ & $87 \%$ \\
\hline
\end{tabular}

Table 2. Refraction condition of students.

\begin{tabular}{ccc}
\hline Variables & $\mathrm{N}$ & Diopter mean \pm SD \\
\hline Total student & $338(100 \%)$ & $-2.17 \pm 1.86$ \\
Hyperopia & $8(2 \%)$ & $1.33 \pm 1.08$ \\
Emmetropia & $69(20 \%)$ & $-0.31 \pm 0.32$ \\
Myopia & $261(77 \%)$ & $-2.77 \pm 1.67$ \\
Without glasses & $107(32 \%)$ & $-1.58 \pm 0.78$ \\
With glasses & $154(46 \%)$ & $-3.60 \pm 1.62$ \\
Good fitting & $88(26 \%)$ & $-3.42 \pm 1.39$ \\
Poor fitting & $66(20 \%)$ & $-3.95 \pm 1.86$ \\
\hline
\end{tabular}




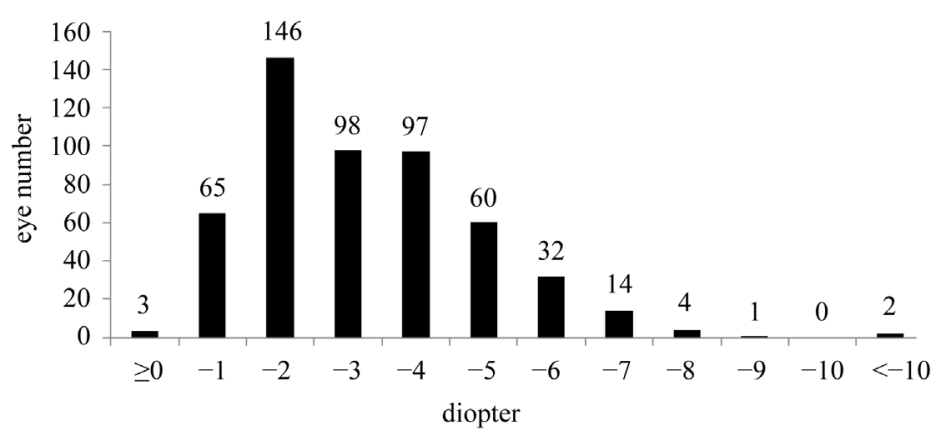

(a)

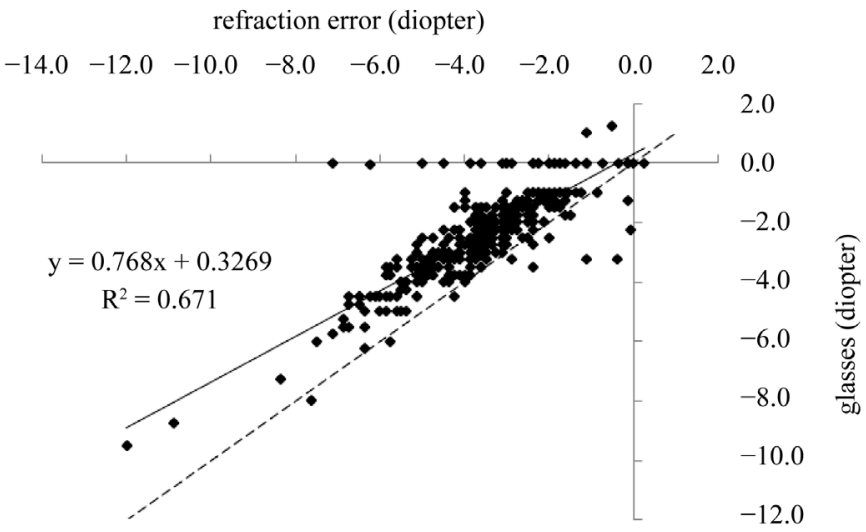

(b)

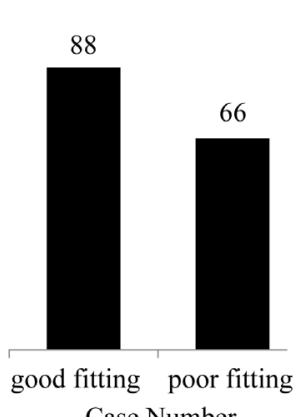

Case Number

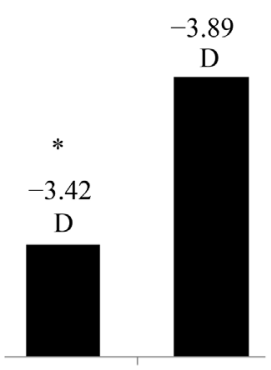

good fitting poor fitting

Refraction error

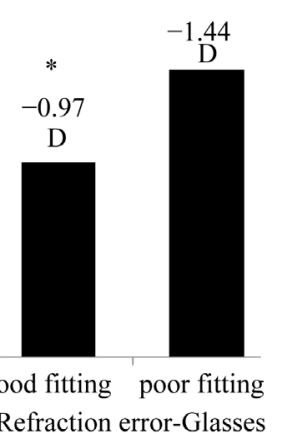

Refraction error-Glasses

(c)

\begin{abstract}
Figure 2. (a) Among the myopia group under the autorefraction examination, 214 eyes (41.00\%) belonged in the low myopia group $(0--3 D), 255$ eyes $(48.85 \%)$ included in the moderate myopia group ( $-3 \mathrm{D}--6 \mathrm{D})$, and 53 eyes $(10.15 \%)$ were in the high myopia group $(<-6 \mathrm{D})$; (b) By the lineal regression analysis, the relationship within the myopia refraction and spectacle prescription revealed a strong association $\left(\mathrm{R}^{2}=0.671, \mathrm{p}<0.01\right)$. The spectacle prescription generally presented under correction by $75 \%$ in this study. - -, dash line stand for the line of equivalence; (c) One hundred and fifty-four students had spectacle prescriptions, including 88 good fitting and 66 poor fitting. Those students with poor fitting spectacles had mean refraction of $-3.95 \mathrm{D}$ (SD \pm $1.86 \mathrm{D}$ ), compared to mean refraction of $-3.42 \mathrm{D}$ ( $\mathrm{SD} \pm 1.39 \mathrm{D})$ in good fitting group. Meanwhile, the subtraction of spectacle prescription from refraction errors showed a lower mismatch in the good fitting group. ${ }^{*} \mathrm{p}<0.05$, compared to poor fitting group.
\end{abstract}

$\pm 0.23 \mathrm{D},-3.04 \mathrm{D} \pm 0.19 \mathrm{D}$, and $-2.37 \mathrm{D} \pm 0.35 \mathrm{D}$, respectively. The students with exotropia and exophoria were found to be more myopic compared to the ones with orthotropia $(\mathrm{p}<0.05)$. No such differences could be detected in esophoria, esotropia and heterotropia groups (Figure 3(b)). The mean refraction in the group with heterotropia was $-3.32 \mathrm{D}(\mathrm{SD} \pm 1.14)$ and was the highest one among all the other groups, but the limited case 
Table 3. Effect of risk factors of myopia on diopter, multiple linear regression analyses $(\mathrm{n}=330)$.

\begin{tabular}{lccc}
\hline & $\beta^{\dagger} \pm \mathrm{SE}^{\#}$ & $\mathrm{p}$ value & $95 \% \mathrm{CI}$ \\
\hline Gender & $-0.083 \pm 0.178$ & 0.10 & $-0.647-0.053$ \\
Suitability of glasses & $-0.123 \pm 0.178$ & $0.01^{*}$ & $-0.792--0.092$ \\
Head position & $-0.028 \pm 0.218$ & 0.58 & $-0.620-0.345$ \\
Stereoacuity & $-0.025 \pm 0.242$ & 0.63 & $-0.594-0.358$ \\
Eye positions & & & $-1.84--0.45$ \\
$\quad$ Exotropia vs. orthotropia & $-0.169 \pm 0.354$ & $0.00^{*}$ & $-1.82-1.39$ \\
$\quad$ Esotropia vs. orthotropia & $-0.013 \pm 0.815$ & 0.79 & $-2.15--1.40$ \\
$\quad$ Exophoria vs. orthotropia & $-0.494 \pm 0.190$ & $0.00^{*}$ & $-2.82-0.39$ \\
$\quad$ Esophoria vs. orthotropia & $-0.074 \pm 0.815$ & 0.14 & $-4.54--0.06$ \\
Heterotropia vs. orthotropia & $-0.100 \pm 1.14$ & $0.04^{*}$ & \\
\hline
\end{tabular}

${ }^{\dagger} \beta$, standardized partial regression coefficient; ${ }^{*} \mathrm{SE}$, standard error; ${ }^{*} \mathrm{p}<0.05$.

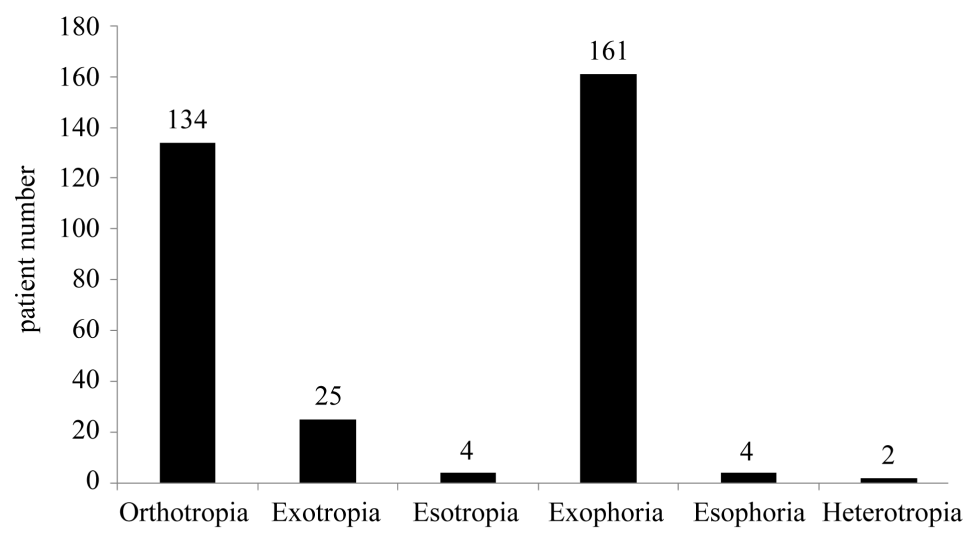

(a)

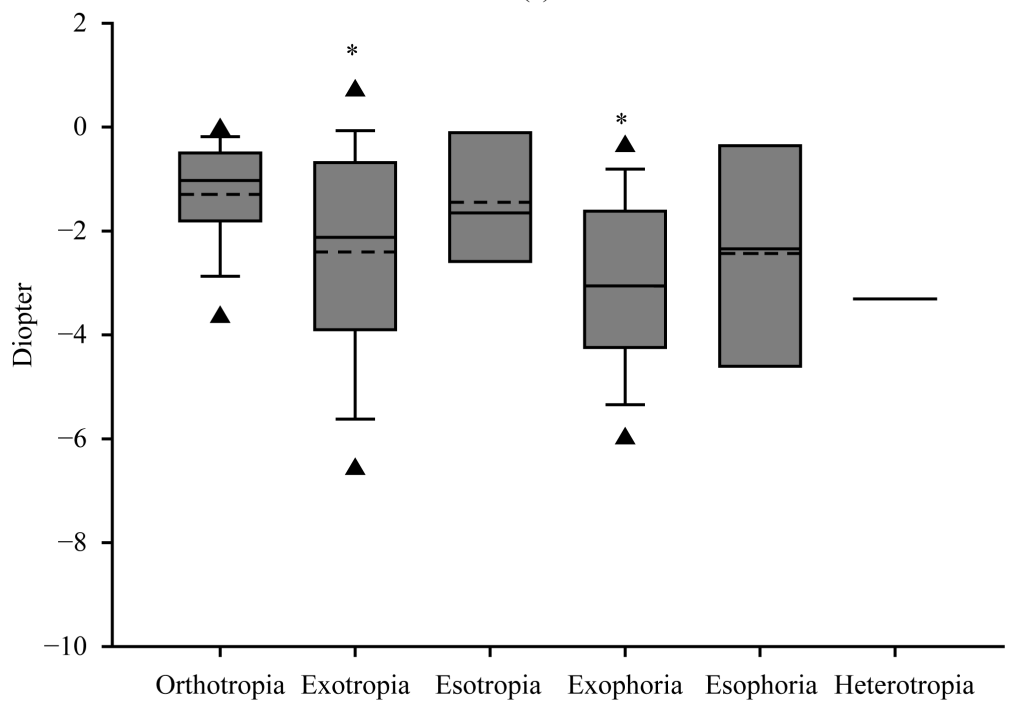

(b)

Figure 3. (a) The distribution of each eye position; (b) The box-and-whisker plot of diopter of myopia versus different eye position. The students with exotropia and exophoria were found to be more myopic compared to the ones with orthotropia $(\mathrm{p}<0.05)$. - - -, dash line stand for mean. $\boldsymbol{\Delta}$, stand for 5 th and 95 th percentile. ${ }^{*} \mathrm{p}<0.05$, compared with diopter of orthotropia. 
number $(\mathrm{n}=2)$ failed to prove the difference.

The effect of suitability of spectacles was investigated. 42.2\% (66/154) of these students who had poor fitting spectacles had significantly decreased refraction as compared to those in the good fitting spectacles group, (mean refraction $-3.95 \mathrm{D} \pm 1.86 \mathrm{D}$ versus $-3.42 \mathrm{D} \pm 1.39 \mathrm{D}$, respectively) $(\mathrm{p}<0.05)$ (Figure 2(c)).

For the stereoacuity test (Table 4), gender did not play a significant role, nor did the refraction condition or spectacle wearing. However, the ocular alignment correlated with the stereoacuity $(p=0.03)$. The stereoacuity in the group of exotropia and exophoria were significantly more limited than the one in the group of orthotropia $(\mathrm{p}=0.02 \& 0.03)$ (Figure 4).

Table 4. Effect of risk factors of stereoacuity on myopia, eye position and diopter on multiple linear regression analyses $(\mathrm{n}=$ 330).

\begin{tabular}{|c|c|c|c|}
\hline & $\beta^{\dagger} \pm \mathrm{SE}^{\#}$ & $\mathrm{p}$ value & $95 \% \mathrm{CI}$ \\
\hline Gender & $0.055 \pm 0.041$ & 0.32 & $-0.040-0.122$ \\
\hline Suitability of glasses & $-0.032 \pm 0.042$ & 0.56 & $-0.110-0.058$ \\
\hline Head position & $0.145 \pm 0.056$ & $0.00^{*}$ & $0.038-0.259$ \\
\hline Diopters & $-0.030 \pm 0.013$ & 0.63 & $-0.032-0.019$ \\
\hline \multicolumn{4}{|l|}{ Eye positions } \\
\hline Exotropia vs. orthotropia & $0.126 \pm 0.083$ & $0.03^{*}$ & $0.015-0.340$ \\
\hline Esotropia vs. orthotropia & $-0.036 \pm 0.188$ & 0.52 & $-0.493-0.249$ \\
\hline Exophoria vs. orthotropia & $0.099 \pm 0.049$ & 0.13 & $-0.023-0.172$ \\
\hline Esophoria vs. orthotropia & $-0.038 \pm 0.189$ & 0.50 & $-0.501-0.243$ \\
\hline Heterotropia vs. orthotropia & $-0.041 \pm 0.265$ & 0.45 & $-0.720-0.322$ \\
\hline
\end{tabular}

${ }^{\dagger} \beta$, standardized partial regression coefficient; ${ }^{\#} \mathrm{SE}$, standard error; ${ }^{*} \mathrm{p}<0.05$.

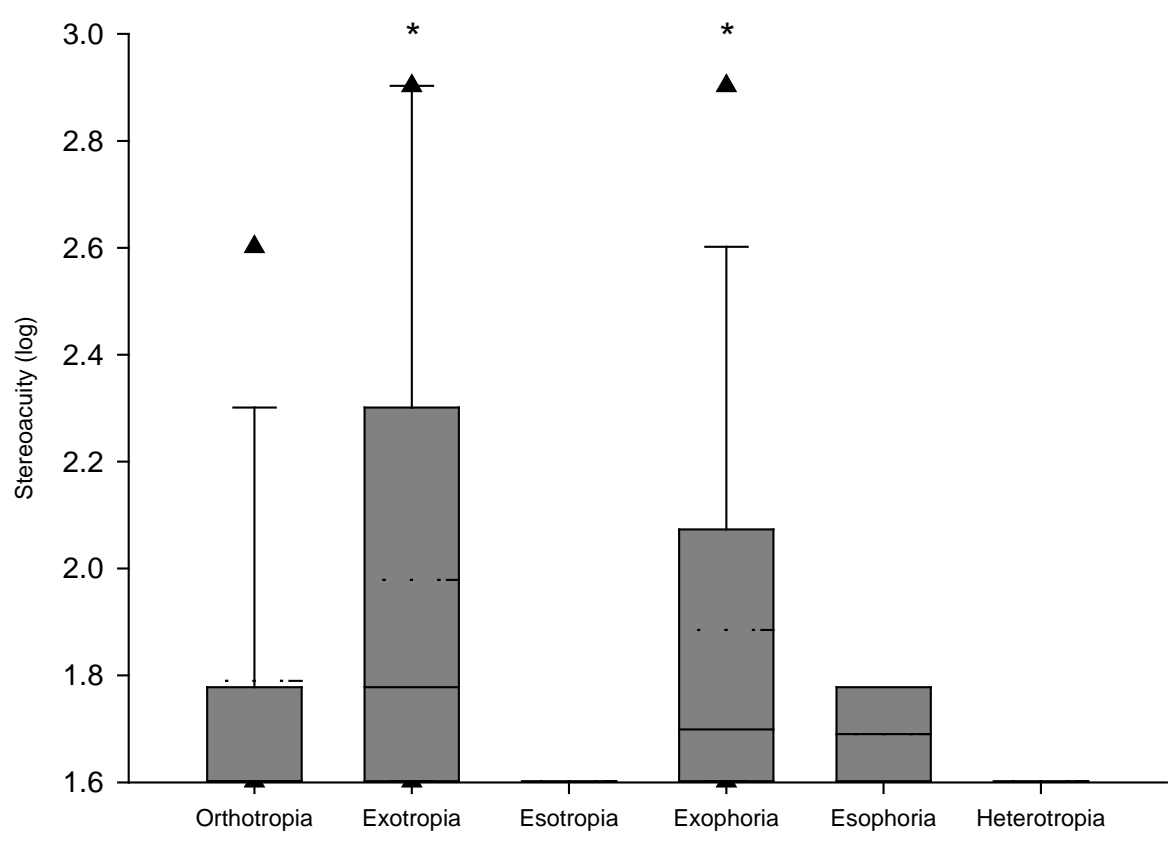

Figure 4. The box-and-whisker plot of stereoacuity versus different eye position. The stereoacuity in the group of exotropia and exophoria were significantly more limited than the one in the group of orthotropia $(\mathrm{p}=0.02 \& 0.03)$. - - -, dash line for mean. $\boldsymbol{\Delta}$, stand for 5 th and 95 th percentile. ${ }^{*} \mathrm{p}<0.05$, compared with stereoacuity of rthotropia. 


\section{Discussion}

The most significant findings in the present study were that spectacle suitability and ocular alignment played a degree of association in the refractive error and stereoacuity in the juvenile population in southern Taiwan. Mailiao junior high school is located in the rural area of Taiwan; however, the prevalence of myopia was as high as $78 \%$. Compared with the metropolitan area in Taiwan with a massively intensive education system, the students in rural region did not have too much reading work and had more time for outdoor activities. However, the prevalence of refractive error was still high. Although literature has suggested that watching TV and playing video games or working on the computer at home did not differ between myopes and emmetropes [8], lack of modern pediatric ophthalmologists or optometrists service in this rural area might play a role in the high refraction error. The students usually had spectacles from frame stores and thus could not have their refraction error properly addressed. Education of safe and efficient spectacle prescription was an issue for all the ophthalmologists and the care-providers from schools to prevent further damage and myopia progression.

The under-fitting-spectacles could not provide a good visual function for the students and might result in high myopia. Students wore unsuitable spectacles usually had some problem such as frame tilt and distortion could cause eye soreness, headache, and reading problems. Improper pupillary distance would result in vision distortion from the prism effect of the two myopic lenses, which could cause eye strain, tearing and redness of the eyes. For example, when an exophoria patient wore the spectacles with PD longer than needed, the patients needed to do more convergence in order to compensate the prism effect from the lenses. Burian et al. reported the exotropia was divergence excess and convergence insufficiency [26]. Mohney and Huffaker [27] found children with convergence insufficiency represented a relatively common form of exotropia, comprising $11.5 \%$ of the study patients. In those exophoria patients, the two eyes did not focus together at all times. The defocused image might have effects in the peripheral vision to trigger the myopia progression. Furthermore, Green et al. [22] advocated patients with exophoria often converted more pseudomyopia in order to avoid crossed diplopia, the weak interni call for extra stimulation. The stimulus, besides being sent to the converging muscles, might be sent to an equal amount to the ciliary muscles, causing sufficient accommodation, not only to correct the hyperopia, but to even overcorrect it, and produce a pseudomyopoia [24]. In our study, the participants with exophoria were found to be more myopic.

The association between exophoria and myopia became more obvious when considering ethnicity. Govindan et al. and Greenberg et al. claimed the XT (exotropia):ET (esotropia) ratio was 35:65 in USA [16] [17]; and Robaei et al. also revealed the ratio was 35:65 in Australia [28]. However, recent studies suggest that Asian strabismus patterns were different from those in the Western societies. Chia et al. showed the XT:ET ratio was 73:27 in Chinese Singaporeans [19]. Yu et al. found the changing patterns of strabismus in Hong Kong in the past two decades with XT:ET ratio 27.4:20.3 [20]. In Korea, Rah et al. estimated the intermittent exotropia is the most common type of strabismus and occurred more prevalently in Asian than in Caucasian populations [24]. In addition, Chia et al. further demonstrated differential patterns of refractory errors in XT and ET groups. Forty three percent (43\%) of the XT groups were myopia and $4 \%$ were hyperopia. In contrast, myopia was present in $22 \%$ of ET groups while $28 \%$ were moderate hyperopes [19]. Maths et al. also claimed that esotropia showed a more pronounced hypermetropia than exotropia cases [29]. In the present study, exotrope (exophoria and exotropia) groups carried higher myopia, as contrasted to ET groups who had less myopia. In the regression model, the XT was displayed to play a role in high myopia. Hence we suggested that exophoria was a predisposing factor of myopia, and deserved further investigation and intervention.

Lens transparency is important to provide a good vision function; poor lens transparency usually induces eye strain, itching and soreness. From our study, the effect of poor-fitting spectacles resulted in a poor visual acuity, which suggests that the ophthalmologists and the public health workers need to work on proper and good-fitting spectacles.

The other important findings were that stereoacuity was associated with ocular malalignment. In Taiwan, the students usually had visual acuity examination twice a year in the school by school nurses. O'Donoghue et al. stated that visual acuity measures did not reliably detect childhood refractive error [30]. Robinson et al. also found the measurement of the validity of a vision screening program should contain the visual acuity, stereoacuity, and ocular alignment [31] but the school nurses and health care providers in rural areas were not familiar with the ocular alignment assessment. Titmus test provided a good alternative to demonstrate the eye malalignment because there was a good correlation between the stereoacuity and ocular alignment. We suggested that students undergo both the visual acuity and the stereoacuity test for yearly survey. This approach could provide 
important information regarding the myopia and ocular alignment for early intervention.

Several limitations should be acknowledged in this study. First, refraction errors were determined in a noncylcoplegic pattern. Because this study was a school-based design by cross-sectional survey, the cylcoplegic agents were not prescript in the school and the students also refused to dilate the pupil because of their previous experience of blurriness of close objects and photophobia. A definition of myopia for adults from the Eye Diseases Prevalence Research Group was utilized [23]. Even though the estimation of refractive error condition was not cycloplegic, the relationship between the myopia and spectacles suitability and ocular alignment should still parallel. Further study is suggested to document the association of the myope and ocular alignment under the cycloplegic condiion. Second, this study was limited by its small number. More public health surveys and longtime cohort studies are suggested.

\section{Conclusion}

The prevention and treatment for adolescent myopia should be highlighted as an important public health problem. It is urgent and critical to seek effective treatment to ameliorate the progression of myopia to prevent ocular diseases in Taiwan. Further, the poor-fitting spectacles cause the deteriorating factors for myopia progression. The myopic adolescents with eye position of exophoria and exotropia have more tendencies for high myopia.

\section{Acknowledgements}

We would like to acknowledge that the study was funded by a grant from the Taiwan Formosa Plastic Company (FCRPF 690011). We also thank all participants living around the western coastal region in Yunlin County who helped in the success of this study and the grant from the Chang Gang Memorial Hospital (CMRPG 6B0131).

\section{Competing Interests}

The authors declare that they have no competing interests.

\section{References}

[1] Li, S.M., Ji, Y.Z., Wu, S.S., et al. (2011) Multifocal versus Single Vision Lenses Intervention to Slow Progression of Myopia in School-Age Children: A Meta-Analysis. Survey of Ophthalmology, 56, 451-460. http://dx.doi.org/10.1016/j.survophthal.2011.06.002

[2] Pan, C.W., Ramamurthy, D. and Saw, S.M. (2012) Worldwide Prevalence and Risk Factors for Myopia. Ophthalmic and Physiological Optics, 32, 3-16. http://dx.doi.org/10.1111/j.1475-1313.2011.00884.x

[3] Yu, L., Li, Z.K., Gao, J.R., Liu, J.R. and Xu, C.T. (2011) Epidemiology, Genetics and Treatments for Myopia. International Journal of Ophthalmology, 4, 658-669.

[4] Leo, S.W. and Young, T.L. (2011) An Evidence-Based Update on Myopia and Interventions to Retard Its Progression. Journal of AAPOS, 15, 181-189. http://dx.doi.org/10.1016/j.jaapos.2010.09.020

[5] Lin, L.L., Shih, Y.F., Hsiao, C.K. and Chen, C.J. (2004) Prevalence of Myopia in Taiwanese Schoolchildren: 1983 to 2000. Annals Academy of Medicine Singapore, 33, 27-33.

[6] Wojciechowski, R. (2011) Nature and Nurture: The Complex Genetics of Myopia and Refractive Error. Clinical Genetics, 79, 301-320. http://dx.doi.org/10.1111/j.1399-0004.2010.01592.x

[7] Chen, C.J., Cohen, B.H. and Diamond, E.L. (1985) Genetic and Environmental Effects on the Development of Myopia in Chinese Twin Children. Ophthalmic Paediatrics and Genetics, 6, 353-359. http://dx.doi.org/10.3109/13816818509004128

[8] Mutti, D.O., Mitchell, G.L., Moeschberger, M.L., Jones, L.A. and Zadnik, K. (2002) Parental Myopia, near Work, School Achievement, and Children’s Refractive Error. Investigative Ophthalmology \& Visual Science, 43, 3633-3640.

[9] Rose, K.A., Morgan, I.G., Smith, W., Burlutsky, G., Mitchell, P. and Saw, S.M. (2008) Myopia, Lifestyle, and Schooling in Students of Chinese Ethnicity in Singapore and Sydney. Archives of Ophthalmology, 126, 527-530. http://dx.doi.org/10.1001/archopht.126.4.527

[10] Song, Y.Y., Wang, H., Wang, B.S., Qi, H., Rong, Z.X. and Chen, H.Z. (2011) Atropine in Ameliorating the Progression of Myopia in Children with Mild to Moderate Myopia: A Meta-Analysis of Controlled Clinical Trials. Journal of Ocular Pharmacology and Therapeutics, 27, 361-368. http://dx.doi.org/10.1089/jop.2011.0017

[11] Lam, C.S., Goldschmidt, E. and Edwards, M.H. (2004) Prevalence of Myopia in Local and International Schools in 
Hong Kong. Optometry \& Vision Science, 81, 317-322. http://dx.doi.org/10.1097/01.opx.0000134905.98403.18

[12] Yoon, K.C., Mun, G.H., Kim, S.D., Kim, S.H., Kim, C.Y., Park, K.H., et al. (2011) Prevalence of Eye Diseases in South Korea: Data from the Korea National Health and Nutrition Examination Survey 2008-2009. Korean Journal of Ophthalmology, 25, 421-433. http://dx.doi.org/10.3341/kjo.2011.25.6.421

[13] Dirani, M., Chan, Y.H., Gazzard, G., Hornbeak, D.M., Leo, S.W., Selvaraj, P., et al. (2010) Prevalence of Refractive Error in Singaporean Chinese Children: The Strabismus, Amblyopia, and Refractive Error in Young Singaporean Children (STARS) Study. Investigative Ophthalmology \& Visual Science, 51, 1348-1355. http://dx.doi.org/10.1167/iovs.09-3587

[14] Vitale, S., Ellwein, L., Cotch, M.F., Ferris III, F.L. and Sperduto, R. (2008) Prevalence of Refractive Error in the United States, 1999-2004. JAMA Ophthalmology, 126, 1111-1119. http://dx.doi.org/10.1001/archopht.126.8.1111

[15] Mavracanas, T.A., Mandalos, A., Peios, D., Golias, V., Megalou, K., Gregoriadou, A., et al. (2000) Prevalence of Myopia in a Sample of Greek Students. Acta Ophthalmologica Scandinavica, 78, 656-659. http://dx.doi.org/10.1034/j.1600-0420.2000.078006656.x

[16] Greenberg, A.E., Mohney, B.G., Diehl, N.N. and Burke, J.P. (2007) Incidence and Types of Childhood Esotropia: A Population-Based Study. Ophthalmology, 114, 170-174. http://dx.doi.org/10.1016/j.ophtha.2006.05.072

[17] Govindan, M., Mohney, B.G., Diehl, N.N. and Burke, J.P. (2005) Incidence and Types of Childhood Exotropia: A Population-Based Study. Ophthalmology, 112, 104-108. http://dx.doi.org/10.1016/j.ophtha.2004.07.033

[18] Matsuo, T. and Matsuo, C. (2005) The Prevalence of Strabismus and Amblyopia in Japanese Elementary School Children. Ophthalmic Epidemiology, 12, 31-36. http://dx.doi.org/10.1080/09286580490907805

[19] Chia, A., Roy, L. and Seenyen, L. (2007) Comitant Horizontal Strabismus: An Asian Perspective. British Journal of Ophthalmology, 91, 1337-1340. http://dx.doi.org/10.1136/bjo.2007.116905

[20] Yu, C.B., Fan, D.S., Wong, V.W., Wong, C.Y. and Lam, D.S. (2002) Changing Patterns of Strabismus: A Decade of Experience in Hong Kong. British Journal of Ophthalmology, 86, 854-856. http://dx.doi.org/10.1136/bjo.86.8.854

[21] Lambert, S.R. (2002) Are There More Exotropes than Esotropes in Hong Kong? British Journal of Ophthalmology, 86, 835-836. http://dx.doi.org/10.1136/bjo.86.8.835

[22] Green, A.S. (1912) The Value of Prisms in Eye Strain. California State Journal of Medicine, 10, 453-455.

[23] Kempen, J.H., Mitchell, P., Lee, K.E., et al. (2004) The Prevalence of Refractive Errors among Adults in the United States, Western Europe, and Australia. JAMA Ophthalmology, 122, 495-505. http://dx.doi.org/10.1001/archopht.122.4.495

[24] Jung, J.W. and Lee, S.Y. (2010) Comparison of the Clinical Characteristics of Intermittent Exotropia in Children and Adults. Korean Journal of Ophthalmology, 24, 96-100. http://dx.doi.org/10.3341/kjo.2010.24.2.96

[25] Smith, S.J., Leske, D.A., Hatt, S.R. and Holmes, J.M. (2012) Stereoacuity Thresholds before and after Visual Acuity Testing. Ophthalmology, 119, 164-169. http://dx.doi.org/10.1016/j.ophtha.2011.06.041

[26] Burian, H.M. (1966) Exodeviations: Their Classification, Diagnosis and Treatment. American Journal of Ophthalmology, 62, 1161-1166. http://dx.doi.org/10.1016/0002-9394(66)92570-0

[27] Mohney, B.G. and Huffaker, R.K. (2003) Common Forms of Childhood Exotropia. Ophthalmology, 110, $2093-2096$. http://dx.doi.org/10.1016/j.ophtha.2003.04.001

[28] Robaei, D., Rose, K.A., Kifley, A., Cosstick, M., Ip, J.M. and Mitchell, P. (2006) Factors Associated with Childhood Strabismus: Findings from a Population-Based Study. Ophthalmology, 113, 1146-1153. http://dx.doi.org/10.1016/j.ophtha.2006.02.019

[29] Abrahamsson, M., Fabian, G. and Sjostrand, J. (1992) Refraction Changes in Children Developing Convergent or Divergent Strabismus. British Journal of Ophthalmology, 76, 723-727. http://dx.doi.org/10.1136/bjo.76.12.723

[30] O’Donoghue, L., Rudnicka, A.R., McClelland, J.F., Logan, N.S. and Saunders, K.J. (2012) Visual Acuity Measures Do Not Reliably Detect Childhood Refractive Error-An Epidemiological Study. PLoS ONE, 7, e34441. http://dx.doi.org/10.1371/journal.pone.0034441

[31] Robinson, B., Bobier, W.R., Martin, E. and Bryant, L. (1999) Measurement of the Validity of a Preschool Vision Screening Program. American Journal of Public Health, 89, 193-198. http://dx.doi.org/10.2105/AJPH.89.2.193 
Scientific Research Publishing (SCIRP) is one of the largest Open Access journal publishers. It is currently publishing more than 200 open access, online, peer-reviewed journals covering a wide range of academic disciplines. SCIRP serves the worldwide academic communities and contributes to the progress and application of science with its publication.

Other selected journals from SCIRP are listed as below. Submit your manuscript to us via either submit@scirp.org or Online Submission Portal.
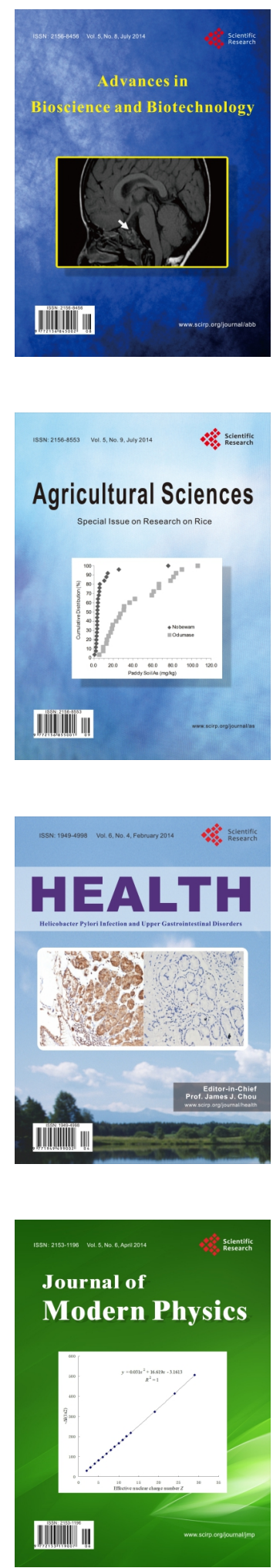
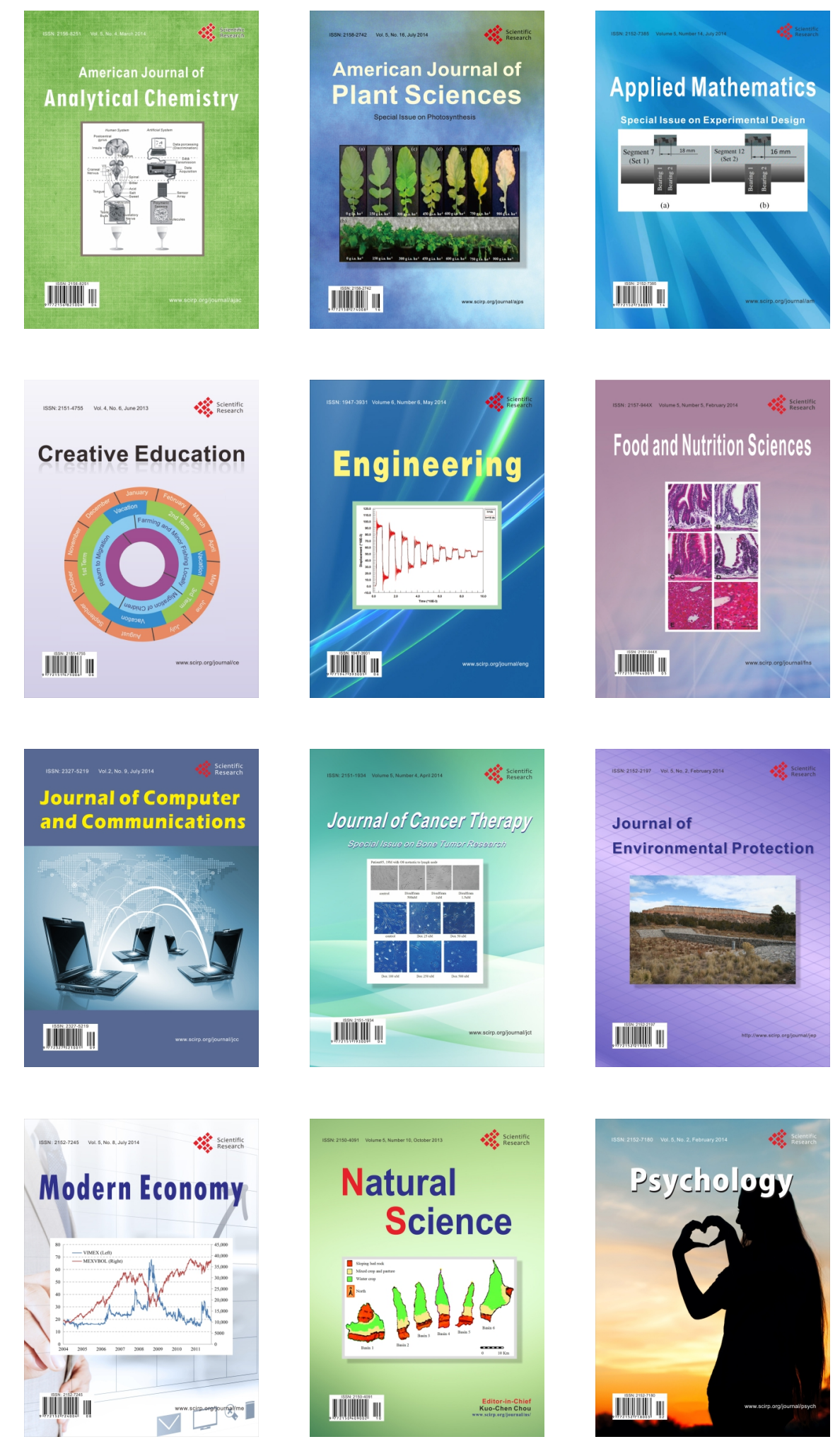